\title{
CARACTERIZAÇÃO FENOLÓGICA DE VARIEDADES DO TIPO MURCOTT EM TRÊS PORTA-ENXERTOS ${ }^{1}$
}

\author{
DANILO VALÉRIO BARBASSO², MÁRIO JOSÉ PEDRO JÚNIOR ${ }^{3}$, ROSE MARY PIO4
}

\begin{abstract}
RESUMO - O estudo do desenvolvimento das plantas relacionado com as condições climáticas de uma região permite a elaboração de modelos de previsão que podem ser úteis na programação de colheita. Esses modelos possibilitam prever o início da safra e a duração dos diferentes períodos fenológicos das plantas, assim como auxilia no manejo de práticas agrícolas. Esta pesquisa teve como objetivo estudar variedades de tangerinas do tipo Murcott enxertadas em diferentes porta-enxertos, avaliando a resposta fenológica de cada uma delas em função do acúmulo de graus-dia. O experimento foi conduzido no Centro Avançado de Pesquisa Tecnológica do Agronegócio de Citros Sylvio Moreira/IAC, localizado na cidade de Cordeirópolis-SP, durante a safra 2003-2004. O delineamento utilizado foi o de blocos casualisados e esquema fatorial 5 (variedades copas) x 3 (portaenxertos), com 4 repetições, com uma planta por parcela. As variedades estudadas foram Thomas, Szuwinkon, Szuwinkon x Szinkon-Tizon e Sul da África, tendo como testemunha o tangor Murcott. Essas copas foram enxertadas em limoeiro Cravo, tangerineira Sunki e citrumeleiro Swingle, e plantadas em 1995. Para a caracterização fenológica, foram atribuídas notas de uma escala elaborada para os estádios fenológicos, desde o préflorescimento até a maturação fisiológica dos frutos, determinando as datas de ocorrência das fases reprodutivas das plantas. Com isso, calculouse o acúmulo de graus-dia para os subperíodos fenológicos. Pelas características das combinações, existem diferenças nas respostas das plantas, onde: a) o acúmulo de graus-dia, da antese até ratio 12, variou de 2.272 GD a 2.836 GD, sendo que as tangerinas Szuwinkon, Szuwinkon x SzinkonTizon e Sul da África obtiveram os menores valores ( $\approx 2.318$ GD), a Murcott cerca de 2.462 GD e a tangerina Thomas os maiores valores ( $\approx 2.791$ GD); foram observadas diferenças de 20 dias do florescimento até ratio 12, dependendo da combinação copa/porta-enxerto.
\end{abstract}

Termos para indexação: Citrus, porta-enxertos, fenologia, escala de notas, graus-dia.

\section{PHENOLOGICAL CHARACTERIZATION OF VARIETIES SIMILAR TO MURCOTT GRAFTED ON THREE ROOTSTOCKS}

\begin{abstract}
The relationship between plant growth and climatic conditions make possible to develop harvest forecast models. This work studied varieties of tangerines similar to Murcott tangor grafted on different rootstocks and evaluated for phenological response to accumulation of degreedays (DD). The experiment was conducted at the "Centro Avançado de Pesquisa Tecnológica do Agronegócio de Citros Sylvio Moreira/IAC”, Cordeirópolis SP, during the 2003-04 season. The experiment was designed in random blocks in a factorial scheme of 5 (canopy cultivars) x 3 (rootstocks), with 4 replicates and one tree per plot. The studied varieties were: Thomas, Szuwinkon, Szuwinkon x Szinkon-Tizon, South Africa and the control Murcott tangor. These varieties were grafted on Rangpur lime, Sunki tangerine and Swingle citrumelo, planted in 1995. For the phenological characterization, grades were attributed according to a scale elaborated for the phenological stages, starting on the pre-flowering until the physiological maturation of the fruits. The determination of the dates of each reproductive phase in the studied plants was done. With that, it was possible to calculate the accumulation of degree-days for phenological sub-periods. According to the canopy/rootstock combinations there were differences in tree responses, such as: a) the accumulation of degree-days, from the anthesis to ratio 12, which varied from 2272 to 2836 DD; the Szuwinkon, Szuwinkon x Szinkon-Tizon and South Africa tangerines had the smallest requirement ( $\approx 2328$ DD); the Murcott tangor, intermediate $(\approx 2462$ DD); and the Thomas tangerine, the largest $(\approx 2791)$; it was observed 20 days of differences from flowering to ratio 12, depending of canopy/rootstock combination.
\end{abstract}

Index terms: citrus, rootstocks, phenology, grades of scale, degree-days.

\section{INTRODUÇÃO}

O Brasil é o maior produtor mundial de citros, com mais de 19 milhões de toneladas (FAO, 2004), sendo o Estado de São Paulo o principal pólo produtor, com quase $83 \%$ da produção brasileira (FNP, 2004), gerando, em todos os níveis da cadeia produtiva, mais de 400 mil empregos diretos (Garcia, 1999).

Dentro da fruticultura, o cultivo de tangerinas e seus híbridos vêm crescendo. O Brasil é o terceiro maior produtor, com 1.263.000 toneladas na safra 2003, com área plantada superior a 50 mil hectares, sendo São Paulo o principal Estado produtor, com cerca de 59\% (FNP, 2004; FAO, 2004).

As características físicas e químicas dos frutos variam no decorrer do período de maturação, e essa variação depende, entre outros fatores, das condições meteorológicas durante a formação e a maturação dos frutos, combinação porta-enxerto/variedade copa, a idade da planta, os estresses hídricos e de temperatura, a localização do fruto na árvore, a radiação solar, as práticas de manejo, principalmente a irrigação, a nutrição e o espaçamento entre as plantas (Reuther, 1973; Volpe et al., 2002).
Segundo Cunha Sobrinho et al. (1992) e Albrigo (1992), a temperatura pode ser considerada como fator mais importante do clima dentre aqueles que influenciam na qualidade dos frutos, como, por exemplo, tamanho e formato, coloração da casca e estádio de maturação.

Graus-dia (GD), ou unidades térmicas, é variável apropriada para determinar em diversas regiões o tempo necessário entre o florescimento e a maturação dos frutos, ou qualquer fase fenológica, nas diversas cultivares. GD acumulados têm sido usados para estimar a quantidade de calor exigida para o crescimento e a maturação dos citros (Volpe, 1992; Volpe et al., 2002).

Volpe et al. (2002), durante quatro anos de estudo na região de Bebedouro, verificaram que GD foi a variável que exerceu maior efeito na taxa de maturação dos frutos da primeira? florada de variedades de laranjas-doces (Natal e Valência) de maturação tardia.

O estudo das relações entre o desenvolvimento das plantas e o acúmulo de graus-dia pode ser útil para a programação de colheitas, previsão de início e duração de determinados períodos fenológicos e zoneamento agrícola das variedades. Para os cítricos, já foram descritas, por diversos autores, as fases de desenvolvimento

\footnotetext{
${ }^{1}$ (Trabalho 047/2005). Recebido: 16/03/2005. Aceito para publicação: 17/11/2005. Parte da dissertação do primeiro autor apresentada ao Instituto Agronômico/ IAC.

${ }^{2}$ Eng. Agr. MSc., Fischer S/A - Agroindústria. barbasso@citrosuco.com.br.

${ }^{3}$ Eng. Agr. Dr., Centro de Ecofisiologia e Biofísica/IAC. mpedro@iac.sp.gov.br.

${ }^{4}$ Bióloga, Dra., Centro APTA Citros Sylvio Moreira/IAC. Bolsista CNPq. rose@centrodecitricultura.br
} 
das plantas, como pode ser constatado em Agusti et al. (1997).

Assim sendo, objetivou-se, nesse trabalho, elaborar uma escala de notas para as fases de florescimento e desenvolvimento dos frutos e avaliar a resposta fenológica de variedades do tipo Murcott em diferentes porta-enxertos, em função do acúmulo de graus-dia.

\section{MATERIAL E MÉTODOS}

A pesquisa foi desenvolvida no Centro Avançado de Pesquisa Tecnológica do Agronegócio de Citros Sylvio Moreira/ IAC, que apresenta as seguintes coordenadas geográficas: $22^{\circ} 32^{\prime} \mathrm{S}$ e $47^{\circ} 27^{\prime} \mathrm{O}$, altitude de $639 \mathrm{~m}$ e clima do tipo Cwa, segundo a classificação de Köppen. O solo é do tipo Latossolo Vermelho distrófico típico (EMBRAPA, 1999). A média de precipitação pluvial anual é de 1.375,3 mm, e a média anual da umidade relativa do ar, de $74,2 \%$. A temperatura média anual é de $20,2^{\circ} \mathrm{C}$, sendo a média das máximas igual a $27,5{ }^{\circ} \mathrm{C}$, e a das mínimas $14,5{ }^{\circ} \mathrm{C}$ (Ortolani et al. 1991).

Foram avaliadas as tangerinas Sul da África, Thomas, Szuwinkon e Szuwinkon x Szinkon-Tizon, tendo como testemunha o tangor Murcott. Todas as variedades são originárias de clones nucelares e foram enxertadas sobre os porta-enxertos: tangerineira Sunki, limoeiro Cravo e citrumeleiro Swingle, num total de 15 diferentes combinações copa/porta-enxerto.

O pomar experimental foi plantado em 15 de fevereiro de 1995, com espaçamento de 8 x 4 m, em delineamento de blocos casualizados, com quatro repetições e uma planta por parcela. Essas plantas receberam os tratos rotineiros da cultura, sem o uso de irrigação.

Para caracterização fenológica, foi elaborada uma escala de notas, por meio de fotografias e análises físico-químicas, das principais fases de desenvolvimento reprodutivo das plantas, desde o estádio de borbulha dormente até a maturação fisiológica dos frutos. Os estádios fenológicos considerados foram: (0) botão floral dormente; (1) botão floral visível; (2) flor completa com as pétalas fechadas (cotonete); (3) abertura da flor (antese); (4) pétalas secas e com estilete; (5) sem pétalas e sem estilete; (6) fruto com aproximadamente $3 \mathrm{~cm}$ de diâmetro (bola de gude); (7) fruto com aproximadamente 4,5 cm (bola de pingue-pongue); (8) fruto verde próximo do tamanho final; (9) fruto na mudança de cor verde para amarela; (10) ratio $\geq 12$.

Foram atribuídas notas da escala às plantas, semanalmente, para as quatro orientações: norte, sul, leste e oeste, na altura de 1 a $2 \mathrm{~m}$ do solo, calculando-se um valor médio por planta, com início antes da floração do ano de 2003. As notas de 1 a 9 da escala foram atribuídas quando mais de $50 \%$ dos ramos da planta se apresentavam em determinado estádio fenológico. Já a nota 10 foi atribuída quando, por meio de análises físico-químicas (sólidos solúveis totais (SST) e acidez titulável (AT), os frutos apresentavam relação SST/AT maior ou igual a 12. Para isso, essas análises se iniciaram a partir da atribuição da nota 9, sendo repetida a cada 20 dias.

Foram considerados os estádios fenológicos: 3; 5; 7; 8 e 10, para a caracterização das combinações copa/porta-enxerto e cálculo da duração dos subperíodos correspondentes.

O cálculo de graus-dia (GD), para os diferentes subperíodos, foi feito segundo Villa Nova et al. (1972), pela equação: $G D=\left(T_{\text {MÁx }}\right.$ $\left.-T_{\text {MINN }}\right) / 2-T_{b}$; onde: $\mathrm{T}_{\text {MÁx }}=$ temperatura máxima diária $\left({ }^{\circ} \mathrm{C}\right) ; \mathrm{T}_{\text {MíN }}=$ temperatura mínima diária $\left({ }^{\circ} \mathrm{C}\right) ; \mathrm{T}_{\mathrm{b}}=$ temperatura base $\left(13^{\circ} \mathrm{C}\right)$. $\mathrm{O}$ acúmulo de GD foi feito pela soma do GD diário para cada subperíodo.

Os dados climáticos foram obtidos do Centro de Ecofisiologia e Biofísica, do IAC, para a região de Limeira-SP (Figura $1)$.

A comparação da duração do subperíodo, florescimento até ratio12, foi feita por análise de intervalo de confiança, com 95\% de confiança, segundo Snedecor e Cochraw (1973).

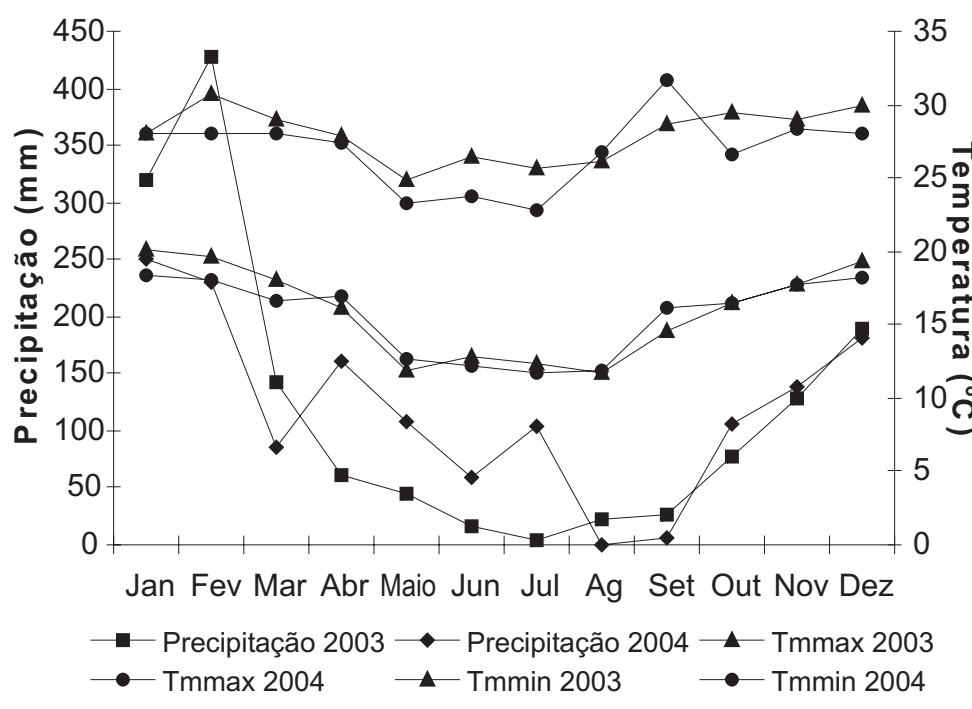

FIGURA 1 - Dados climáticos para a região de Limeira nos anos de 2003 e 2004. Legenda: Tmmáx = temperatura média máxima; Tmmín = temperatura média mínima. Fonte: Centro de Ecofisiologia e Biofísica/IAC

\section{RESULTADOS E DISCUSSÃO}

A escala fenológica desenvolvida para a avaliação dos estádios fenológicos das combinações copas/porta-enxertos encontra-se na Tabela 1. Quando comparada com a escala apresentada por Agusti et al. (1997), observa-se que os autores atribuíram quatro notas (00; 01; 10 e 31) para o período de dormência do botão floral, enquanto a escala mostrada na Tabela 1 indica apenas a nota 0 para essa fase fenológica. As fases de desenvolvimento intermediárias ficaram praticamente correspondentes nas duas escalas. Entretanto, a partir da nota 5 - flores sem pétalas, sem estilete - (Tabela 1), optou-se por maior subdivisão das fases de crescimento do fruto e mudança de coloração, ao contrário das atribuídas por Agusti et al.(1997), que deram preferência para duas delas (72 e 89). Para as variedades aqui estudadas, notou-se a necessidade de atribuir mais cinco notas nas fases finais de desenvolvimento (6; 7; 8; 9 e 10), pois ocorreram diferenças de períodos de crescimento dos frutos, nessas fases, entre variedades que apresentam períodos de colheitas em épocas diferentes.

Assim sendo, essas escalas de notas, contendo fotos e descrições, servem de guias que auxiliam na identificação das fases evolutivas das plantas. Escalas de notas visuais, em nível de campo, para as diferentes fases fenológicas das plantas, podem ser facilmente utilizadas por produtores agrícolas para a determinação do estádio de desenvolvimento das plantas. É muito importante que o agricultor conheça essas fases, pois, para a utilização de produtos fitossanitários e, principalmente, biorreguladores na produção de tangerinas, o momento certo da aplicação pode ser decisivo.

O florescimento das plantas, no pomar experimental, ocorreu por volta de 10 de outubro de 2003 para o tangor Murcott e Thomas, e 20 de outubro de 2003 para as tangerinas Szuwinkon, Szuwinkon x SzinkonTizon e Sul da África.

Na Figura 2, pode ser vista a evolução dos valores médios de ratio para as diferentes combinações copa/porta-enxerto, até alcançarem valores maior ou igual a 12 .

Na Tabela 2, estão apresentados os valores médios de duração dos subperíodos, determinados com auxílio da escala de notas apresentada anteriormente. Verifica-se, de modo geral, no subperíodo 3-5, valores próximos para as tangerinas Szuwinkon e Szuwinkon x Szinkon-Tizon, de 7 a 17 dias, e o tangor Murcott, Thomas e Sul da África, com duração de 15 a 29 dias. No subperíodo 5-7, observam-se os menores valores para o tangor Murcott, de 73 a 83 dias, valores próximos para as tangerinas Szuwinkon, Szuwinkon x Szinkon-Tizon e Sul da África, com duração de 152 a 166 dias, e para Thomas, de 101 a 113 dias. Para o subperíodo 7-8, nota-se a tangerina Sul da África com os menores valores, entre 28 e 36 dias, as tangerinas Thomas, Szuwinkon e Szuwinkon x Szinkon-Tizon, 
TABELA 1 - Escala de notas elaborada para as diferentes fases do desenvolvimento reprodutivo das plantas.

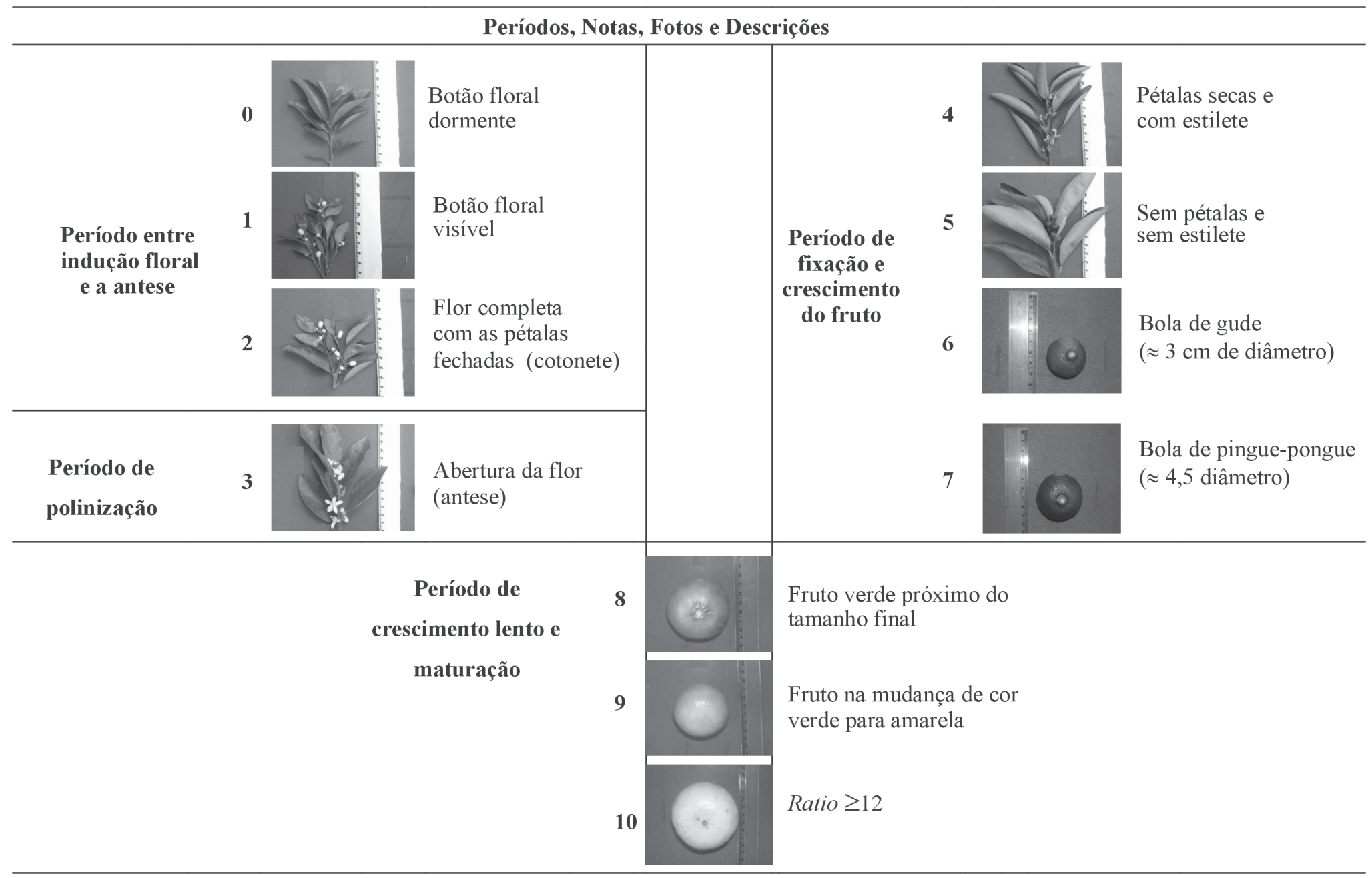

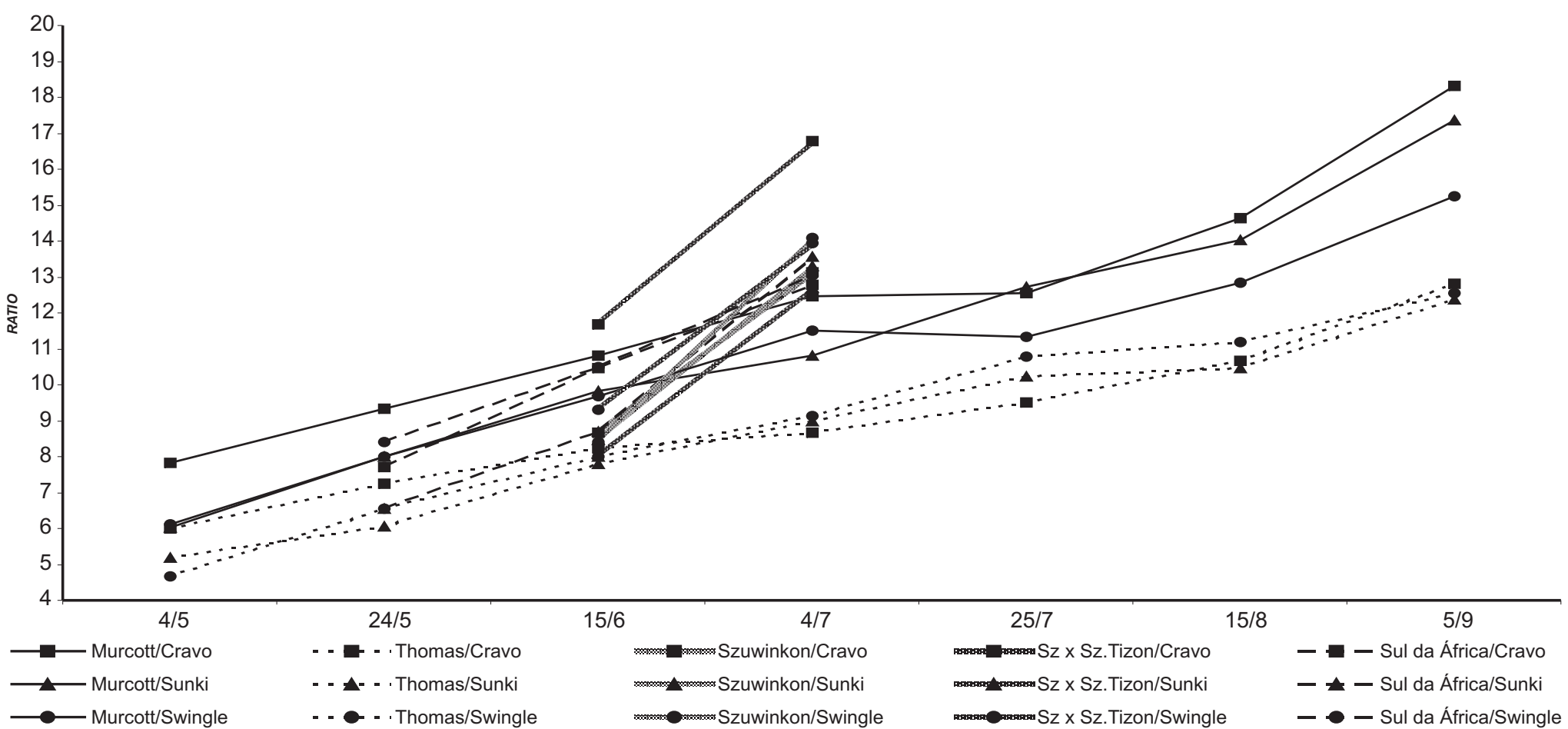

FIGURA 2 - Evolução dos valores médios de ratio, para as diferentes combinações copa/porta-enxerto, até alcançar valor $\geq 12$, safra 2003-2004, Cordeirópolis-SP. Legenda: Sz x Sz.Tizon = Szuwinkon x Szinkon-Tizon.

com 55 a 75 dias, e o tangor Murcott com os maiores valores, de 93 a 99 dias de duração do sub-período 7-8. Já no subperíodo 8-10, as tangerinas se dividiram em durações de 27 a 38 dias para Szuwinkon e Szuwinkon x Szinkon-Tizon, 46 a 65 dias para Sul da África, 93 a 99 dias para Murcott e 135 a 145 para Thomas.

Para melhor visualização, na Figura 3, tem-se um gráfico com os valores médios da duração, em dias, do subperíodo 3-10 (florescimento ratio 12), com seus respectivos intervalos de confiança, para as diferentes combinações copa/porta-enxerto.

A tangerina Thomas teve um número de dias superior às demais tangerinas para atingir o valor de ratio 12 (por volta 335 dias). O tangor Murcott não apresentou diferenças significativas para a duração do 
TABELA 2 - Valores médios da duração dos subperíodos (em dias) das combinações copa/porta-enxerto, na safra 2003-2004, Cordeirópolis-SP.

\begin{tabular}{|c|c|c|c|c|c|c|}
\hline \multirow[b]{2}{*}{ Copa/Porta-enxerto } & \multicolumn{6}{|c|}{ Duração dos subperíodos (em dias) } \\
\hline & $3-5$ & $5-7$ & $7-8$ & $8-10$ & $3-10$ & $\begin{array}{c}\text { Intervalo de } \\
\text { Confiança*(subperíodo } 3-10 \text { ) }\end{array}$ \\
\hline Murcott/Cravo & 24 & 83 & 71 & 97 & 275 & $\pm 9,6$ \\
\hline Murcott/Sunki & 21 & 76 & 96 & 93 & 286 & $\pm 10,9$ \\
\hline Murcott/Swingle & 20 & 73 & 105 & 99 & 297 & $\pm 10,9$ \\
\hline Thomas/Cravo & 27 & 101 & 61 & 145 & 334 & $\pm 7,4$ \\
\hline Thomas/Sunki & 29 & 113 & 57 & 141 & 340 & $\pm 9,6$ \\
\hline Thomas/Swingle & 26 & 112 & 57 & 135 & 330 & $\pm 11,6$ \\
\hline Szuwinkon/Cravo & 7 & 146 & 75 & 27 & 255 & 0 \\
\hline Szuwinkon/Sunki & 10 & 166 & 55 & 38 & 269 & $\pm 9,1$ \\
\hline Szuwinkon/Swingle & 12 & 161 & 55 & 27 & 255 & 0 \\
\hline Szuwinkon x Szinkon-Tizon/Cravo & 13 & 146 & 75 & 18 & 252 & $\pm 9,3$ \\
\hline Szuwinkon x Szinkon-Tizon/Sunki & 15 & 163 & 55 & 38 & 271 & $\pm 7,4$ \\
\hline Szuwinkon x Szinkon-Tizon/Swingle & 17 & 156 & 55 & 27 & 255 & $\pm 4,4$ \\
\hline Sul da África/Cravo & 25 & 147 & 28 & 65 & 265 & $\pm 12,8$ \\
\hline Sul da África/Sunki & 15 & 159 & 28 & 59 & 261 & $\pm 9,9$ \\
\hline Sul da África/Swingle & 21 & 152 & 36 & 46 & 255 & 0 \\
\hline
\end{tabular}

*com 95\% de confiança de que a média esteja no intervalo.

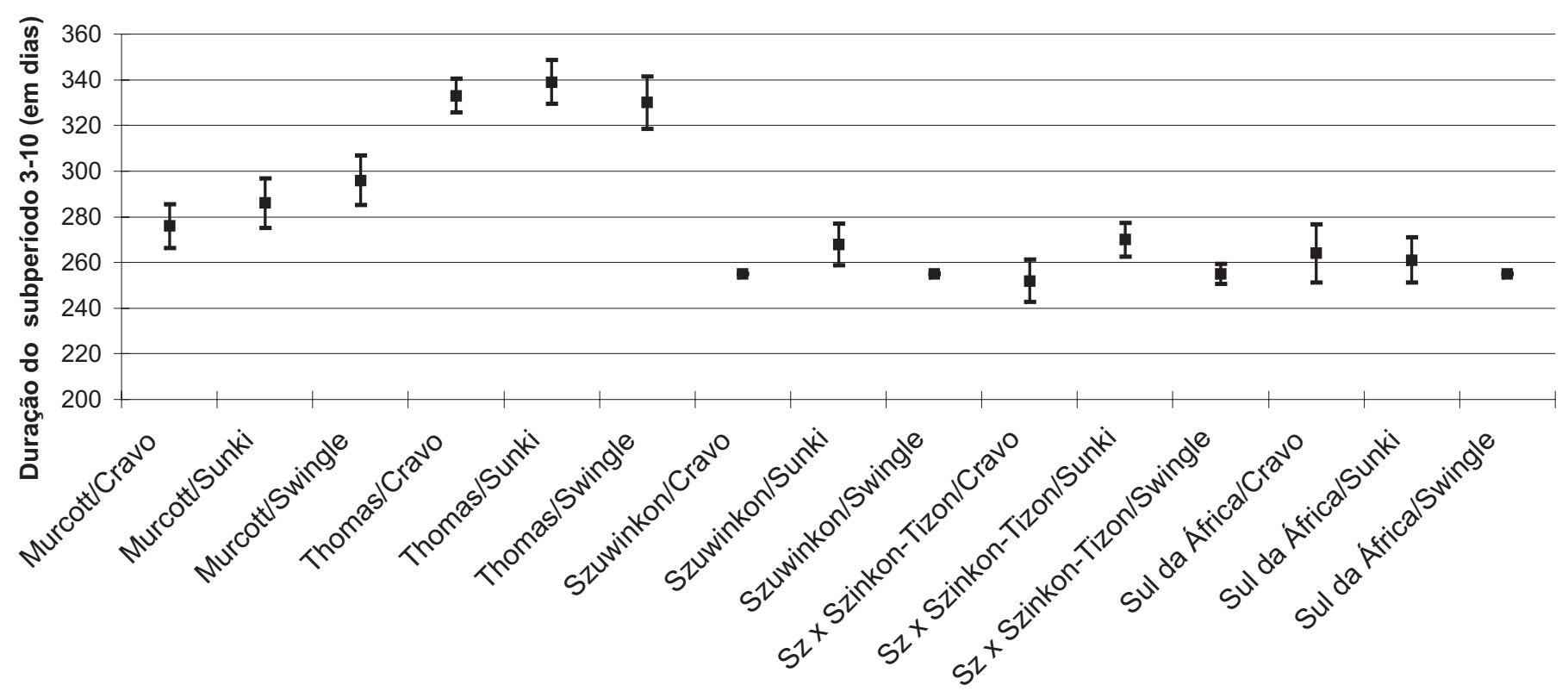

FIGURA 3 - Intervalo de confiança para a duração, em dias, do subperíodo 3-10, safra 2003-2004, Cordeirópolis-SP. Legenda: Sz x Szinkon-Tizon = Szuwinkon x Szinkon-Tizon.

TABELA 3 - Valores médios de graus-dia acumulados nos subperíodos, para as combinações copa/porta-enxerto, na safra 2003-2004, Cordeirópolis-SP.

\begin{tabular}{|c|c|c|c|c|c|c|}
\hline \multirow[b]{2}{*}{ Copa/Porta-enxerto } & \multicolumn{6}{|c|}{ Graus-dia acumulados nos subperíodos } \\
\hline & $3-5$ & $5-7$ & $7-8$ & $8-10$ & $3-10$ & $\begin{array}{l}\text { Intervalo de Confiança* } \\
\text { (subperíodo 3-10) }\end{array}$ \\
\hline Murcott/Sunki & 220 & 834 & 934 & 448 & 2436 & $\pm 37,2$ \\
\hline Murcott/Swingle & 201 & 798 & 1024 & 465 & 2488 & $\pm 20,1$ \\
\hline Thomas/Cravo & 261 & 1089 & 590 & 827 & 2767 & $\pm 68,6$ \\
\hline Szuwinkon/Cravo & 88 & 1527 & 501 & 163 & 2279 & 0 \\
\hline Szuwinkon/Sunki & 115 & 1709 & 318 & 206 & 2348 & $\pm 18,2$ \\
\hline Szuwinkon/Swingle & 131 & 1666 & 318 & 163 & 2278 & 0 \\
\hline Szuwinkon x Szinkon-Tizon/Cravo & 149 & 1527 & 501 & 97 & 2274 & $\pm 65,4$ \\
\hline Szuwinkon x Szinkon-Tizon/Sunki & 160 & 1681 & 318 & 206 & 2365 & $\pm 27,1$ \\
\hline Szuwinkon x Szinkon-Tizon/Swingle & 180 & 1611 & 318 & 163 & 2272 & $\pm 49,6$ \\
\hline
\end{tabular}

*com 95\% de confiança de que a média esteja no intervalo. 
subperíodo 3-10, quando comparado com as tangerinas Szuwinkon, Szuwinkon x Szinkon-Tizon e Sul da África, com exceção para a combinação Murcott/Swingle (Figura 3).

Para os porta-enxertos, não foram observadas diferenças na duração do subperíodo 3-10. Porém notam-se as maiores diferenças para a influência dos porta-enxertos nas variedades-copa, entre Murcott/Cravo e Murcott/Swingle, e entre Szuwinkon x Szinkon-Tizon/Cravo e Szuwinkon $\mathrm{x}$ Szinkon-Tizon/Sunki, onde, para ambos, foram observados aproximadamente 20 dias de diferença. Mesmo não sendo uma diferença significativa, um intervalo de 20 dias entre a colheita de um talhão para outro pode ser relevante no planejamento do pomar e venda do produto.

Na Tabela 3 e na Figura 4, estão apresentados os valores médios do acúmulo de graus-dia para o subperíodo 3-10, com seus respectivos intervalos de confiança, para as combinações copa/porta-enxerto. Notamse, de modo geral, três grupos de tangerinas que diferiram quanto ao número de graus-dia. Tem-se, no primeiro grupo, a tangerina Thomas com os maiores valores compreendidos entre 2.746 e 2.836 graus-dia, seguida pelo tangor Murcott, no segundo grupo, com valores médios entre 2.436 e 2.488 graus-dia, e no terceiro grupo, as tangerinas Szuwinkon, Szuwinkon x Szinkon-Tizon e Sul da África com os menores valores (2.272 a 2.365 graus-dia). Fazendo-se uma analogia com as laranjeiras, para Ortolani et al. (1991), o primeiro grupo encontrado, neste experimento, estaria com valores próximos às laranjas meia-estação (3.100 GD), o tangor Murcott sendo considerado como uma variedade precoce (2.500 GD), e as demais tangerinas estudadas, como superprecoces, com valores de GD abaixo dos encontrados por esses autores, em laranjeiras.

Por meio das análises físico-químicas, pôde-se observar que a tangerina Thomas tem índice de maturidade ideal menor que 12, pois este índice só foi atingido no momento em que já haviam ocorrido quedas de frutos. Este fato pode explicar a diferença na duração do sub-período 3-10, da tangerina Thomas com as demais variedades. Entretanto, a escolha do ratio 12 foi feita tendo como padrão o tangor Murcott.



FIGURA 4 - Intervalo de confiança para o número médio de graus-dia acumulados no subperíodo 3-10, safra 2003-2004, Cordeirópolis-SP. Legenda: Sz x Szinkon-Tizon = Szuwinkon x Szinkon-Tizon.

\section{CONCLUSÕES}

Considerando o período estudado, pode-se concluir que:

1. Para o tangor Murcott, são necessários, aproximadamente, 2.462 graus-dia, do florescimento até ratio 12 .

2. Considerando ratio 12, as variedades Szuwinkon, Szuwinkon x Szinkon-Tizon e Sul da África são mais precoces do que o tangor Murcott.

3. O ratio 12 não é indicado para a tangerina Thomas. Seus frutos apresentam características internas diferentes da Murcott, com porcentagens de acidez e sólidos solúveis mais elevadas. Thomas poderá constituir-se em uma boa opção de plantio.

\section{REFERÊNCIAS}

AGRIANUAL 2004: Anuário da agricultura brasileira. São Paulo: FNP Consultoria \& Agroinformativos, 2004. p.241-283.

AGUSTI, M., ZARAGOZZA, S.; BLEIHOLDER, H.; BUHR, L.; HACK, H.; KLOSE, R.; STAUB, R. Adaptation de l‘ échelle BBCH à la description des stades phénologiques des agrumes du genre Citrus. Fruits, v.52, n.5, 287-295, 1997.

ALBRIGO, G. Influências ambientais no desenvolvimento dos frutos cítricos. In: SEMINÁRIO INTERNACIONAL DE CITROS FISIOLOGIA, 2., 1992. Anais... Campinas: Fundação Cargill, 1992. p. 100-106.

CUNHA SOBRINHO, AP. da; SOARES FILHO, W S. dos S.; PASSOS, O. S.; CALDAS, R.C. Influência de porta-enxertos na qualidade do fruto de laranjeira 'Baianinha' sob condições tropicais. Revista Brasileira de Fruticultura, Cruz das Almas, v. 14, n. 3, p. 99-104. 1992.
EMBRAPA. Centro Nacional de Pesquisa de Solos. Sistema brasileiro de classificação de solos. Rio de Janeiro: Embrapa Solos, 1999, 412p.

FAO. Production Yearbook, 2004. Disponível em: <http://apps.fao.org.>. Acesso em: $1^{\circ}$ dez. 2004.

GARCIA, A. Operação de guerra. Revista Fundecitrus, Ribeirão Preto, n. 92, p. 2, 1999.

ORTOLANI, A. A.; PEDRO JR, M.J.; ALFONSI, R.R. Agroclimatologia e o cultivo dos citros. In: RODRIGUEZ, O.; VIÉGAS, F.; POMPEU JUNIOR, J.; AMARO, A.A. (Ed.). Citricultura brasileira. Campinas: Fundação Cargill, 1991. v. 1, p. 153-188.

REUTHER, W. Climate and citrus behavior. In: REUTHER, W. (Ed.). The citrus industry. Riverside: University of California, 1973. v. 3, cap. 9, p. 280-337.

SNEDECOR, G.W.; COCHRAW, W.G. Statistical methods. Iowa: State University, 1973. 593p.

VILLA NOVA, N.A; PEDRO JR, M.J.; PEREIRA, A R.; OMETTO, J.C. Estimativa de graus-dia acumulados acima de qualquer temperatura base, em função das temperaturas: máximas e mínima. São Paulo: Universidade de São Paulo- Instituto de Geografia, 1972. 8p. (Caderno de Ciências da Terra, 30).

VOLPE, C.A. Fenologia dos citros. In: SEMINÁRIO INTERNACIONAL DE CITROS: FISIOLOGIA, 2., 1992, Bebedouro. Anais... Campinas: Fundação Cargill, 1992. p.107-121.

VOLPE, C.A.; SCHÖFFEL, E. R.; BARBOSA, J. C. Influência da soma térmica e da chuva durante o desenvolvimento de laranjas 'Valência' e 'Natal' na relação entre sólidos solúveis e acidez e no índice tecnológico do suco. Revista Brasileira de Fruticultura, Jaboticabal, v. 24, n. 2, p. 436-441, 2002. 